\title{
OVERVIEW
}

\section{Phase Transformation and Microstructure of Partially-Stabilized Zirconia*}

\author{
By T. Sakuma**
}

\begin{abstract}
Phase transformations and the resultant microstructures of partially-stabilized zirconia (PSZ) are briefly reviewed with a special interest in the nature of phase transformations. The martensitic tetragonal-to-monoclinic transformation, which plays a principal role in toughening of PSZ, accompanies lattice defects such as twins or dislocations in the product phase $\mathrm{m}-\mathrm{ZrO}_{2}$. The diffusionless cubicto-tetragonal (c-t) transformation is characterized by two different microstructures; one with the domain structure whose boundaries have curvilinear features showing the contrast of anti-phase domain boundaries in ordered alloys, and the other with thin-plates or lenticular features. It seems that the diffusionless c-t transformation is always completed by an initial development of domain structure over the entire region of samples. The thin plates or lenticular features may be subsequently formed by the strain accommodation. The nature of the diffusionless c-t transformation is the second order phase transition. The precipitation of $\mathrm{t}-\mathrm{ZrO}_{2}$ in the $\mathrm{c}-\mathrm{ZrO}_{2}$ matrix is commonly found in alloys heat-treated in the cubic/tetragonal two-phase region. Together with the usual precipitation structures, the modulated or tweed structure is also formed at an early stage of aging. The origin of these microstructures, and the nature of the diffusional reaction or precipitation is discussed in this paper.
\end{abstract}

(Received September 13, 1988)

Keywords: phase transformation, martensitic transformation, precipitation, microstructure, partially-stabilized zirconia

\section{Introduction}

Pure zirconia exhibits very poor mechanical properties and thermal shock resistance, so that it is hopeless to use pure zirconia as structural ceramics. However, Garvie and his coworkers have found a new zirconia ceramics with excellent strength and toughness in $1975^{(1)}$. The improvement of mechanical properties is attained by a suitable addition of cubic-stabilizing oxides such as $\mathrm{CaO}, \mathrm{Y}_{2} \mathrm{O}_{3}, \mathrm{CeO}_{2}$, etc. It is essential to retain an unstable tetragonal phase $\left(\mathrm{t}-\mathrm{ZrO}_{2}\right)$ at room temperature by "alloying" for realizing high strength and toughness. This $\mathrm{t}-\mathrm{ZrO}_{2}$ is transformed into a stable monoclinic phase $\left(\mathrm{m}-\mathrm{ZrO}_{2}\right)$ under the tensile stress around crack tip during fracture. It has been

* This overview is invited by the Trans. JIM Editorial Committee.

** Department of Materials Science, Faculty of Engineering, The University of Tokyo, 7-3-1 Hongo, Bunkyo-ku, Tokyo 113, Japan. believed that the tetragonal-to-monoclinic (t-m) transformation absorbs a part of fracture energy and then contributes to high strength and toughness ${ }^{(2)-(7)}$. The toughening mechanism is thus referred to as the transformation toughening.

Toughened zirconia ceramics obtained so far may be classified into three groups as shown in Fig. ${ }^{(8)}$. Partially-stabilized zirconia (PSZ) generally has a two-phase microstructure consisting of $\mathrm{t}-\mathrm{ZrO}_{2}$ and cubic $\left(\mathrm{c}-\mathrm{ZrO}_{2}\right)$ phase. Tetragonal zirconia polycrystals (TZP) are the fine-grained polycrystals of a single tetragonal phase, which has been fabricated by several Japanese companies. The dispersion of toughened zirconia into other ceramics is also useful in improving their mechanical properties. This type of ceramics is termed the composite ceramics, in which the dispersion is usually made by mechanical alloying. Figure 1 is a very rough drawing of microstructure of three zirconia-toughened ceramics. Actually, the microstructure of PSZ changes markedly 


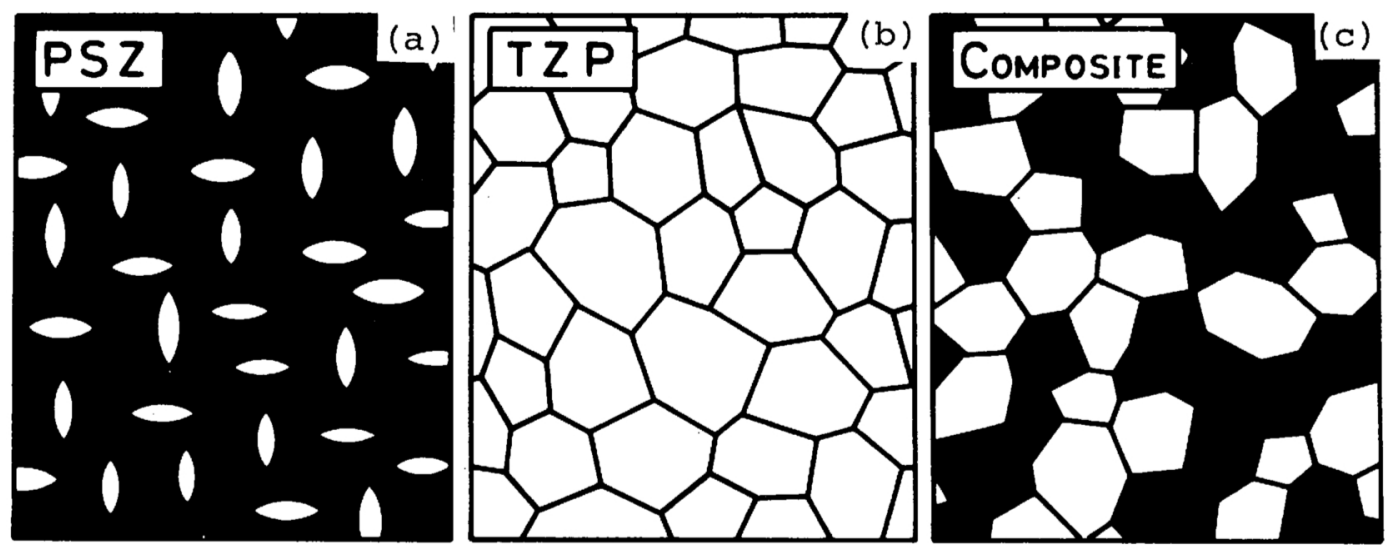

Fig. 1 Three types of toughened zirconia ceramics ${ }^{(8)}$.

with various factors such as the type of cubic-stabilizing oxides, composition, grain size, heat treatment etc. The background of zirconia as engineering ceramics has already been described in several review articles ${ }^{(9)(10)}$. In this paper, the importance of microstructural control of PSZ is mainly introduced, and the microstructural origin is discussed from the knowledge of phase transformation and precipitation.

\section{Crystal Structure of Three Phases Relevant to Microstructural Control}

Pure zirconia has three polymorphisms; c$\mathrm{ZrO}_{2}, \mathrm{t}-\mathrm{ZrO}_{2}$ and $\mathrm{m}-\mathrm{ZrO}_{2}$. The $\mathrm{c}-\mathrm{ZrO} \mathrm{r}_{2}$ is the high-temperature phase, which has a cubic fluorite-type structure. In this structure, $\mathrm{Zr}^{4+}$ ions are located in the center of a cube whose corners are occupied by $\mathrm{O}^{2-}$ ions. The eight $\mathrm{O}^{2-}$ ions are on an equal distance from the $\mathrm{Zr}^{4+}$ ion. The $\mathrm{c}-\mathrm{ZrO}_{2}$ is transformed into $\mathrm{t}-\mathrm{ZrO}_{2}$ at $2643 \mathrm{~K}^{(11)}$. The $\mathrm{t}-\mathrm{ZrO}_{2}$ has a slightly-distorted fluorite structure, with a unit cell drawn in Fig. $2^{(12)(13)}$. The $\mathrm{Zr}^{4+}$ ions have the eightfold coordination in $\mathrm{t}-\mathrm{ZrO}_{2}$ as well as $\mathrm{c}-\mathrm{ZrO}_{2}$. However there are two sets of distances between $\mathrm{Zr}^{4+}$ and $\mathrm{O}^{2-}$ ions in $\mathrm{t}-\mathrm{ZrO}_{2}, 0.2455 \mathrm{~nm}$ and 0.2065 $\mathrm{nm}$ at $1523 \mathrm{~K}^{(12)}$. The $\mathrm{O}^{2-}$ ions depicted as filled circles in Fig. 2 are slightly displaced upwards from their position in the cubic fluorite structure, while those drawn by hatched circles are displaced downwards. The oxygen ions' displacement results in tetragonal distortion in

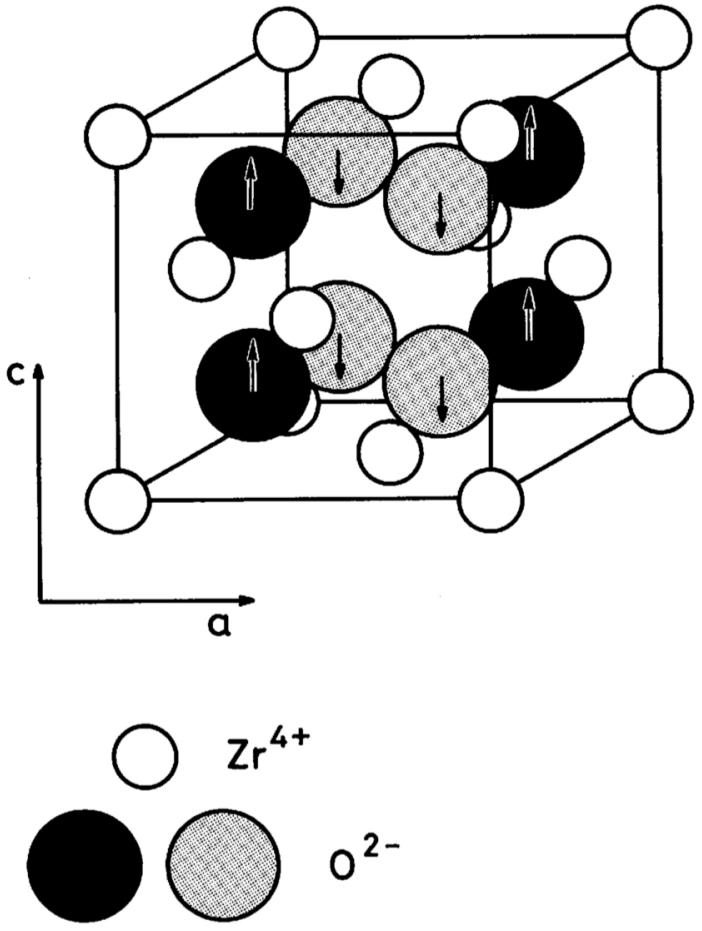

Fig. 2 Crystal structure of tetragonal zirconia.

crystals. The $\mathrm{t}-\mathrm{ZrO}_{2}$ is further transformed into $\mathrm{m}-\mathrm{ZrO}_{2}$ around $1300 \mathrm{~K}$. The $\mathrm{m}-\mathrm{ZrO}_{2}$ has the sevenfold coordination of $\mathrm{Zr}^{4+}$ ions and consists of layers of triangular coordination polyhedra of $\mathrm{O}_{1} \mathrm{Zr}_{3}$ and distorted tetrahedra of $\mathrm{O}_{\mathrm{II}} \mathrm{Zr}_{4}{ }^{(14)}$. The ionic distance between $\mathrm{Zr}^{4+}$ and $\mathrm{O}^{2-}$ ions ranges from $0.205 \mathrm{~nm}$ to $0.228 \mathrm{~nm}$ at room temperature. 
Lattice parameters of these phases have been measured by several workers. Figure 3 is a plot of lattice parameter and cube root of unit cell volume as a function of temperature in $\mathrm{m}-\mathrm{ZrO}_{2}$ and $\mathrm{t}-\mathrm{ZrO}_{2}{ }^{(15)}$. The unit cell volume discontinuously changes at the transition temperature between $\mathrm{m}-\mathrm{ZrO}_{2}$ and $\mathrm{t}-\mathrm{ZrO}_{2}$, so that a considerable volume change occurs during the tetragonal-to-monoclinic transition during cooling.

Figure 4. shows the data of lattice parameter

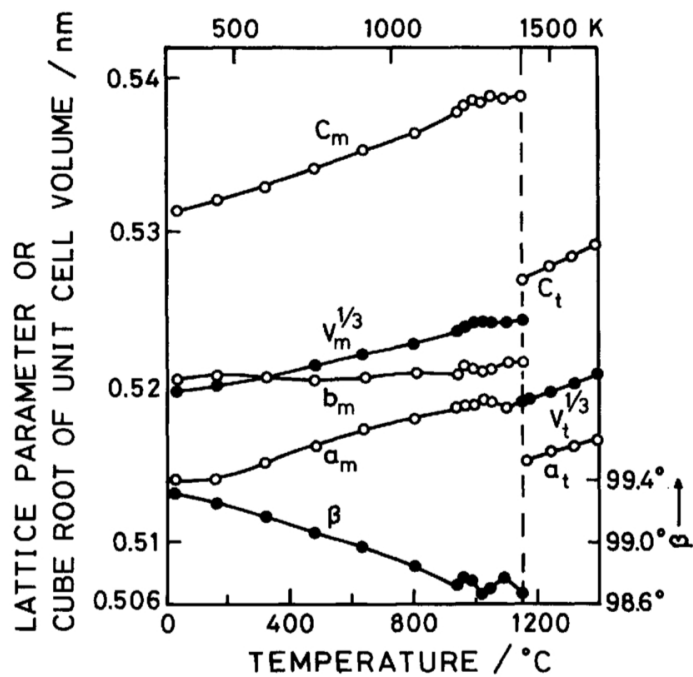

Fig. 3 Lattice parameter and unit cell volume as a function of temperature in $\mathrm{ZrO}_{2}{ }^{(15)}$.

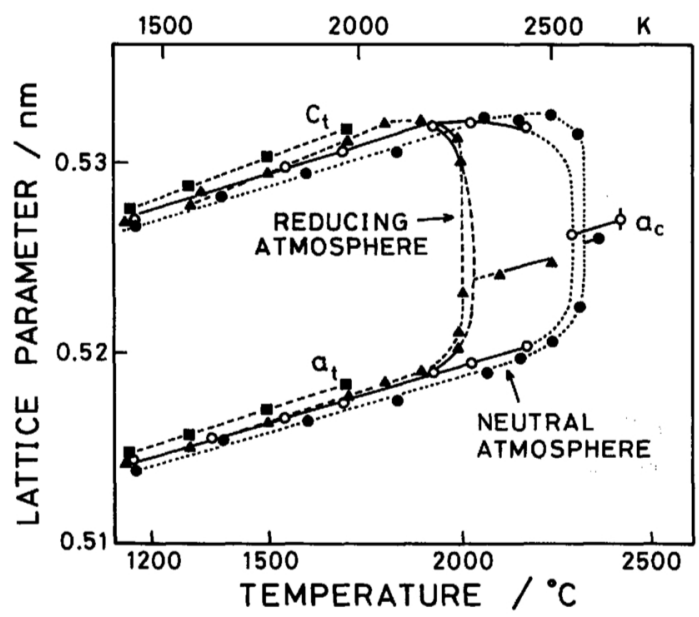

Fig. 4 Variation of lattice parameter with temperature in $\mathrm{t}-\mathrm{ZrO}_{2}$ and $\mathrm{c}-\mathrm{ZrO}_{2}{ }^{(16)}$. change of $\mathrm{t}-\mathrm{ZrO}_{2}$ and $\mathrm{c}-\mathrm{ZrO}_{2}$ with temperature in two different atmospheres ${ }^{(16)}$. The cubic-totetragonal transition appears at about $2570 \mathrm{~K}$ in a neutral atmosphere and at about $2320 \mathrm{~K}$ in a reducing atmosphere, This fact means that c$\mathrm{ZrO}_{2}$ is stabilized in the reducing atmosphere. Both $a_{\mathrm{t}}$ and $c_{\mathrm{t}}$ increase with an increase of temperature except near the transition temperature. Just below the transition temperature, a decrease of $c_{\mathrm{t}}$ and a marked increase of $a_{\mathrm{t}}$ are simultaneously observed, which results in a sharp decrease of tetragonality $c_{\mathrm{t}} / a_{\mathrm{t}}$.

\section{Stabilization of $\mathrm{c}-\mathrm{ZrO}_{2}$ by Alloying}

As mentioned before, a suitable addition of cubic-stabilizing oxide into zirconia is the first requirement to get $\mathrm{PSZ}$ or TZP. Among various cubic-stabilizing oxides, $\mathrm{CaO}, \mathrm{MgO}$, $\mathrm{Y}_{2} \mathrm{O}_{3}$ and $\mathrm{CeO}_{2}$ have been used for commercial materials. The zirconia-rich part of the four binary systems is depicted in Fig. $5^{(17)-(20)}$. Since the equilibrium experiments are difficult at high temperatures above about $2100 \mathrm{~K}$ and also at low temperatures below about $1500 \mathrm{~K}$, these phase diagrams have not firmly been established yet and may be revised in future studies. However, it is possible to get important informations on phase equilibrium and cubic-stabilizing effect of these oxides from Fig. 5. Wide single cubic phase region appears in all four systems, indicating that these oxides act as stabilizer of cubic zirconia. The control of sintering conditions or heat-treatments at temperatures in the cubic/tetragonal twophase region is particularly important in the manufacture of PSZ with excellent mechanical properties.

\section{Microstructure and Mechanical Properties}

The amount of cubic-stabilizing oxides has to be carefully controlled for fabricating toughened zirconia. The composition dependence of strength and toughness has been examined for $\mathrm{ZrO}_{2}-\mathrm{Y}_{2} \mathrm{O}_{3}$ and $\mathrm{ZrO}_{2}-$ $\mathrm{CeO}_{2}$. Figure 6 shows the bend strength of $\mathrm{ZrO}_{2}-\mathrm{Y}_{2} \mathrm{O}_{3}$ alloys as a function of yttria content. 


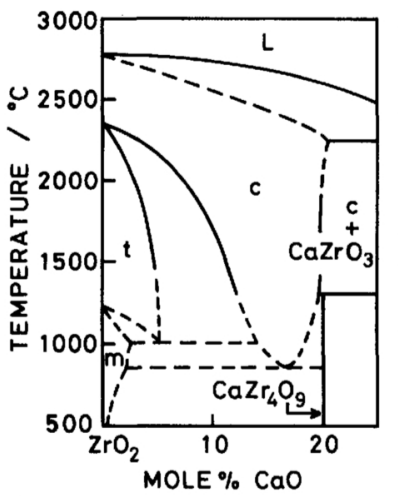

(a) $\mathrm{ZrO}_{2}-\mathrm{CaO}$

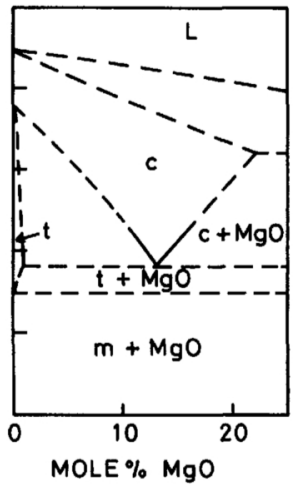

(b) $\mathrm{ZrO}_{2}-\mathrm{MgO}$

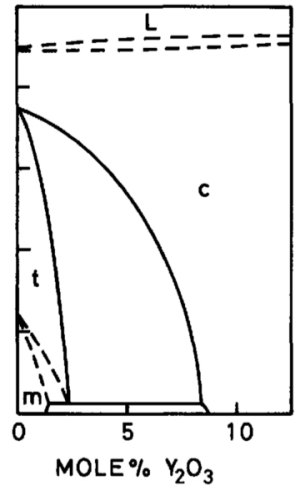

(c) $\mathrm{ZrO}_{2}-\mathrm{Y}_{2} \mathrm{O}_{3}$

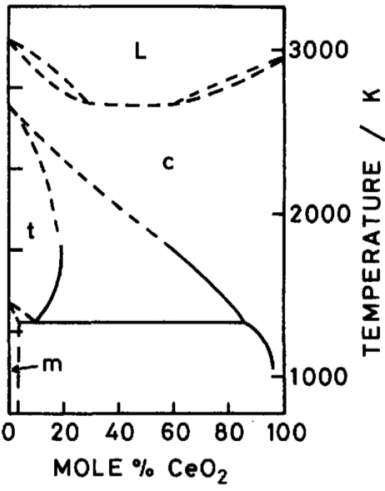

(d) $\mathrm{ZrO}_{2}-\mathrm{CeO}_{2}$

Fig. 5 Phase diagram of binary zirconia systems.

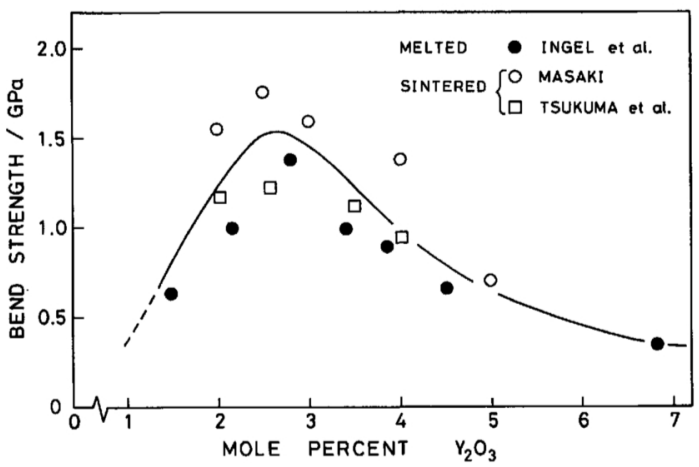

Fig. $6 \mathrm{~A}$ plot of room temperature bend strength of $\mathrm{ZrO}_{2}-\mathrm{Y}_{2} \mathrm{O}_{3}$ against yttria content.

Figure 6 includes the data on skull-melted single crystals ${ }^{(21)}$ and commercially-sintered products $^{(22)(23)}$. The alloys with $2-4 \mathrm{~mol} \% \mathrm{Y}_{2} \mathrm{O}_{3}$ have a bend strength greater than $1.0 \mathrm{GPa}$, which is the highest among various high-performance ceramics.

Figure 7 is a plot of fracture toughness $K_{\text {Ic }}$ against yttria content. Again, the data of skullor arc-melted alloys and of commercial products is compiled in Fig. $7^{(21)-(24)}$. The $K_{\text {Ic }}$ values

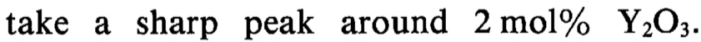
Figures 6 and 7 clearly indicate that the composition optimization is very important in improving the mechanical properties of $\mathrm{ZrO}_{2-}$ $\mathrm{Y}_{2} \mathrm{O}_{3}$ alloys. Similar composition dependence of strength and toughness has also been reported for $\mathrm{ZrO}_{2}-\mathrm{CeO}_{2}$ alloys ${ }^{(26)(27)}$.

Such a marked change in mechanical proper-

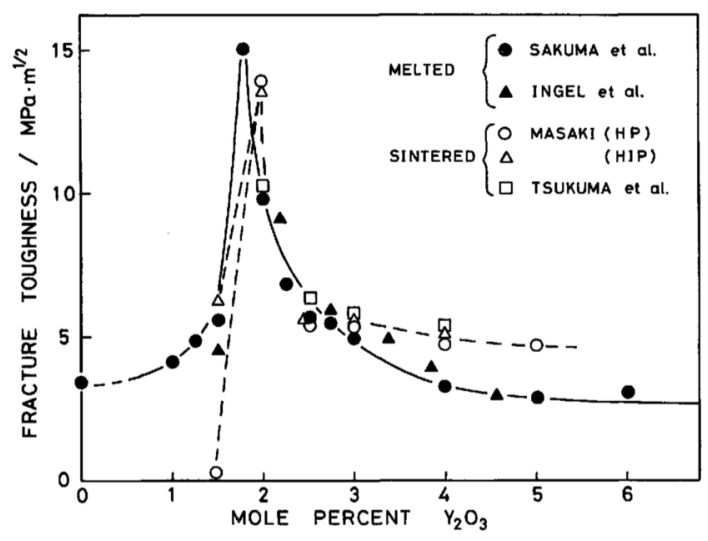

Fig. 7 Fracture toughness of $\mathrm{ZrO}_{2}-\mathrm{Y}_{2} \mathrm{O}_{3}$ as a function of yttria content.

ties with the content of cubic-stabilizing oxides is related to the type of constituent phase and microstructure. Figure 8 shows the microstructures of pure zirconia and three $\mathrm{ZrO}_{2}-\mathrm{Y}_{2} \mathrm{O}_{3}$ alloys which were arc-melted in an argon atmosphere and then cooled fairly rapidly from the melting temperatures ${ }^{(25)}$. Figure $8(a)$ is the twinned $\mathrm{m}-\mathrm{ZrO}_{2}$, (b) the herring-bone structure, (c) the lenticular $\mathrm{t}-\mathrm{ZrO}_{2}$, and (d) the dislocation network in $\mathrm{c}-\mathrm{ZrO}_{2}$. The $\mathrm{t}-\mathrm{ZrO}_{2}$ in Fig. 8(c) contains $5 \mathrm{~mol} \% \mathrm{Y}_{2} \mathrm{O}_{3}$, which is often referred to as $\mathrm{t}^{\prime}-\mathrm{ZrO}_{2}$ for distinguishing from the unstable and transformable $\mathrm{t}-\mathrm{ZrO}_{2}$ containing low $\mathrm{Y}_{2} \mathrm{O}_{3}{ }^{(28)}$.

By comparing the data in Figs. 6 and 7 with the microstructure in Fig. 8, it can be expected 


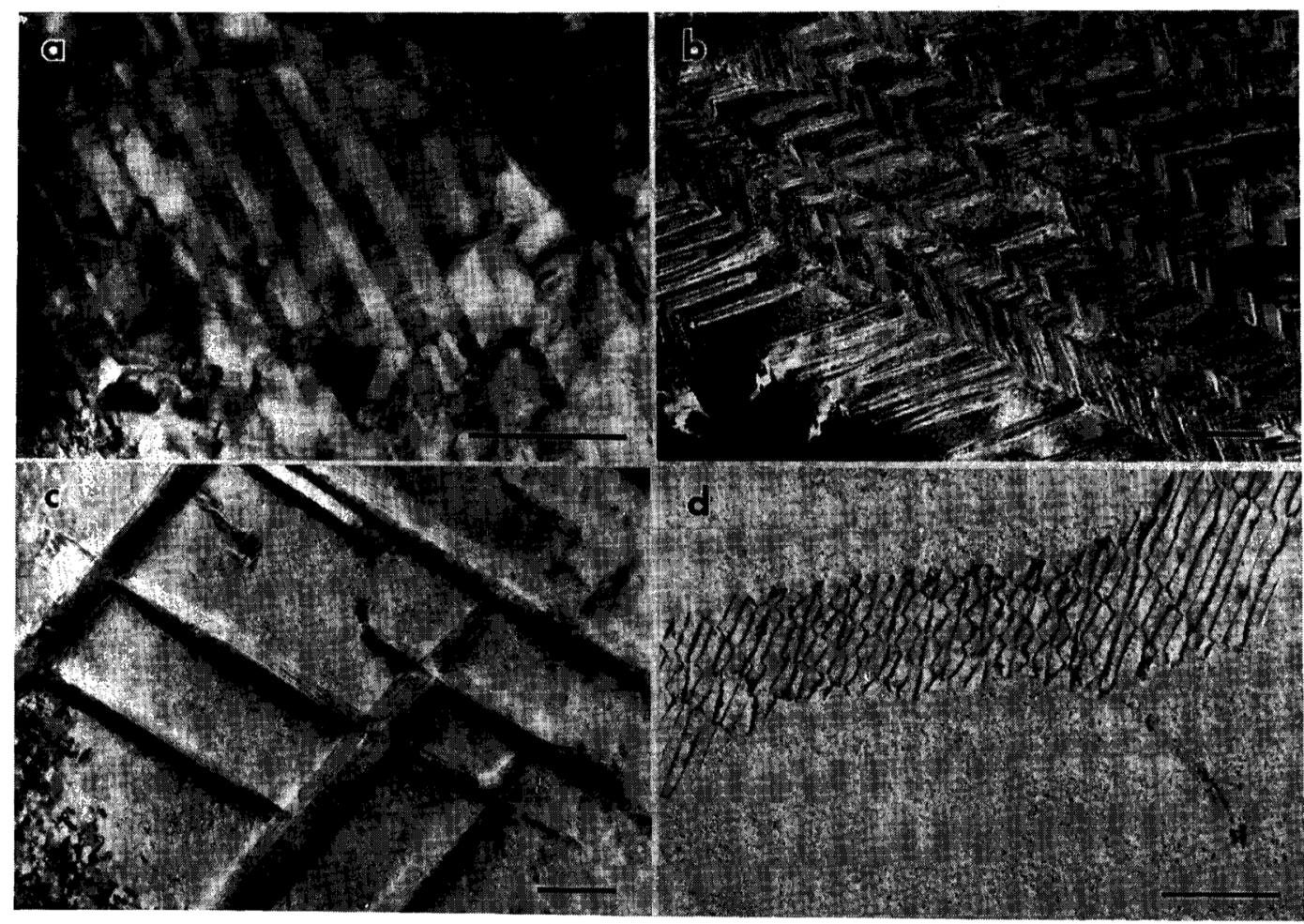

Fig. 8 Microstructure of $\mathrm{ZrO}_{2}-\mathrm{Y}_{2} \mathrm{O}_{3}$ alloys. The yttria content is (a) 0 , (b) $3 \mathrm{~mol} \%$, (c) $5 \mathrm{~mol} \%$ and (d) $8 \mathrm{~mol} \%$, respectively. The alloys were fairly rapidly cooled from melting temperature. The bars in the figure represent $0.5 \mu \mathrm{m}^{(25)}$.

that the microstructure is correlated with the mechanical properties. However, the microstructure-mechanical property relationship can not so easily be understood. For single crystals or very coarse-grained samples, the alloys with high strength and toughness have such a microstructure as shown in Fig. 8(b) ${ }^{(24)(25)}$, while commercial sintered alloys with $2-3 \mathrm{~mol} \% \quad \mathrm{Y}_{2} \mathrm{O}_{3}$ are fine-grained polycrystals consisting of almost featureless t- $\mathrm{ZrO}_{2}$ grains and dislocated or twinned $\mathrm{m}-\mathrm{ZrO}_{2}$ grains ${ }^{(29)}$.

It seems that the highest $K_{\text {Ic }}$ is obtained in alloys containing a small amount of $\mathrm{m}-\mathrm{ZrO}_{2}{ }^{(24)(29)}$. On the other hand, the generation of $\mathrm{m}-\mathrm{ZrO}_{2}$ during annealing causes the strength degradation ${ }^{(30)-(33)}$. In toughened zirconia, the fracture strength is not necessarily proportional to fracture toughness as predicted from the original Griffith's theory ${ }^{(34)}$. The proportionality is only satisfied in low strength and toughness level, where the strength is limited by the size of flaws in original materials. In high $K_{\text {Ic }}$ level, where the transformation toughening is operating, the fracture strength decreases with an increase of $K_{\text {Ic }}{ }^{(35)}$. The microstructure-mechanical property relationship in toughened zirconia has to be carefully examined to take into account these characteristic mechanical properties.

Mechanical properties are also changeable by aging in PSZ. It has been clarified that the bend strength, modulus of rupture and fracture toughness vary with aging at high temperatures $^{(36)-(38)}$. Figure 9 shows the change of bend strength with isothermal aging at $1073 \mathrm{~K}$ in $\mathrm{ZrO}_{2}-8.1 \mathrm{~mol} \% \mathrm{MgO}^{(37)}$. The bend strength takes a peak value of about $350 \mathrm{MPa}$ at aging time around $14.4 \mathrm{ks}$. This type of behavior has been found in modulus of rupture and fracture toughness in $\mathrm{ZrO}_{2}-\mathrm{MgO}$ and $\mathrm{ZrO}_{2}-\mathrm{CaO}$ alloys. The curve of Fig. 9 resembles that of age-hardening in metallic alloys. It has been 


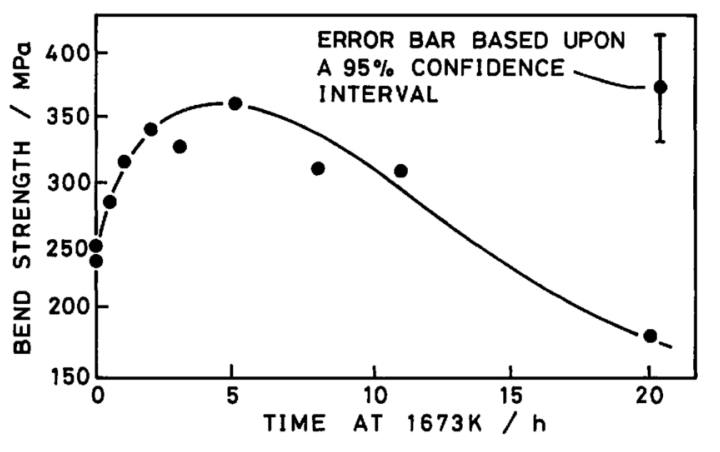

Fig. 9 Change in bend strength with aging time at $1673 \mathrm{~K}$ in $\mathrm{ZrO}_{2}-8.1 \mathrm{~mol} \% \mathrm{MgO}$ alloy ${ }^{(37)}$.

pointed out, however, that the increment of strength and toughness in PSZ should be referred to as age-toughened, but not agehardened, because the increase of these mechanical properties do not reflect the resistance to plastic flow, but to fracture ${ }^{(36)}$.

The microstructure of age-toughened alloys is such as shown in Fig. 1(a); $\mathrm{t}-\mathrm{ZrO}_{2}$ particles are precipitated in the $\mathrm{c}-\mathrm{ZrO}_{2}$ matrix. It has been reported that the optimally aged alloy contains the maximum volume fraction of coherent $\mathrm{t}-\mathrm{ZrO}_{2}$ precipitates, and the overaging is related to the coherency loss of precipitates with the matrix ${ }^{(37)}$. A somewhat different result has been reported in yttria partially-stabilized zirconia (Y-PSZ). In Y-PSZ containing $5 \mathrm{~mol} \% \quad \mathrm{Y}_{2} \mathrm{O}_{3}$, the bend strength was increased by aging at 1473 and $1573 \mathrm{~K}$, but the fracture toughness was almost unchanged by the aging ${ }^{(39)}$. The strengthening by high-temperature aging has been observed only in PSZ with a relatively low or intermediate strength level. Full interpretation of this aging characterisitics in Y-PSZ due to aging remains for future studies.

\section{The Martensitic Tetragonal-to- Monoclinic Transformation}

The equilibrium between $\mathrm{m}-\mathrm{ZrO} \mathrm{O}_{2}$ and $\mathrm{t}-\mathrm{ZrO} \mathrm{r}_{2}$ is in a fairly low temperature region as in Fig. 5 , so that no experimental evidences showing the diffusional reaction between these two phases have been obtained so far. During conventional heat treatments, the tetragonal-tomonoclinic $(\mathrm{t}-\mathrm{m})$ transition takes place by a diffusionless mechanism. The nature of the diffusionless $\mathrm{t}-\mathrm{m}$ transition and the resultant microstructures have originally been examined mainly in pure zirconia. Then, it has been clarified that the transition has the nature of martensitic transformation. The progress of research work on the martensitic t-m transformation until 1974 has completely been reviewed by Subbarao et al. ${ }^{(40)}$ More recently, the martensitic transformation in zirconia alloys has widely been examined, because the transformation is responsible for toughening of PSZ or TZP.

\section{Martensitic nature of the t-m transformation}

There are two types of diffusionless transformation, reconstructive and displacive transformations, in ceramic materials ${ }^{(41)}$. The reconstructive transformation accompanies the destruction and reconstruction of ionic or covalent bonds, which requires a large driving force for transformation. Therefore, this transformation is very sluggish, and a high temperature phase is often supercooled to a low temperature by the suppression of transformation. The displasive transformation is induced without destroying the bonds of parent phase. The relative displacement of crystal lattice on certain crystallographic planes is required for the displasive transformation which occurs much easier than the reconstructive transformation. The diffusionless $t-m$ transformation of zirconia is induced fairly easily probably by relative displacement of constituent ions. The martensitic nature of the transformation has first suggested by Wolten on the basis of the diffusionless and athermal behavior and of thermal hysteresis associated with the transformation ${ }^{(42)}$. Thereafter, a number of the evidence supporting the martensitic nature has been obtained.

The surface relief generated by the t-m transformation has been observed in single and polycrystals of $\mathrm{ZrO}_{2}$ by metallographic examinations $^{(43)(44)}$. It has been reported that the surface relief made of lenticular plates is generated by the forward transformation, but disappears completely by the reverse transformation, i.e. the transformation takes place in a 
reversible manner ${ }^{(44)}$.

Dislocations and/or twins are generally found in $\mathrm{m}-\mathrm{ZrO}_{2}$ produced by the martensitic $\mathrm{t}-\mathrm{m}$ transformation. Figure $8(\mathrm{a})$ is an example of twinned $\mathrm{m}-\mathrm{ZrO}_{2}$. The generation of dislocations or twins may be effective for minimizing the strain energy caused by the transformation. It is considered that the martensitic $t-m$ transformation under the volume constraint takes place by choosing the $\mathrm{m}-\mathrm{ZrO}_{2}$ variants so as to compensate the long range shear stress associated with the transformation ${ }^{(45)}$.

The orientation relationship between parent phase $\mathrm{t}-\mathrm{ZrO}_{2}$ and product phase $\mathrm{m}-\mathrm{ZrO} \mathrm{r}_{2}$ has been examined by various workers ${ }^{(14)(44)(46)-(49)}$. The most probable relationship may be ${ }^{(46)(49)}$

$$
\begin{aligned}
& (100)_{\mathrm{m}} / /(100)_{\mathrm{t}} \\
& {[001]_{\mathrm{m}} / /[001]_{\mathrm{t}}}
\end{aligned}
$$

where the unit cell of $\mathrm{t}-\mathrm{ZrO}_{2}$ is taken to be face-centered tetragonal. It seems that the habit plane is not expressed by a particular crystallographic plane, but habit plane traces parallel to $\{101\}_{\mathrm{t}}$ twin traces are often found ${ }^{(49)}$. The above features are characteristic of martensitic transformation as has been confirmed in various metallic materials. Therefore, the diffusionless $t-m$ transformation of zirconia has generally been accepted as martensitic transformation.

\section{2. $M_{s}$ temperature}

The martensitic $t-m$ transformation accompanies a thermal hysteresis in the range about 150 to $300 \mathrm{~K}$. This hysteresis range depends on various factors and cannot be so firmly defined $^{(40)}$, The thermal hysteresis curves have generally been used to determine the martensite-start $\left(\mathbf{M}_{s}\right)$ and austenite-start $\left(\mathrm{A}_{\mathrm{s}}\right)$ temperatures, and also the $T_{0}$ temperature at which $\mathrm{m}$ $\mathrm{ZrO}_{2}$ and $\mathrm{t}-\mathrm{ZrO}_{2}$ have the same free energy. It has been reported that these temperatures decrease with an increase of $\mathrm{Y}_{2} \mathrm{O}_{3}$ content of $\mathrm{ZrO}_{2}-\mathrm{Y}_{2} \mathrm{O}_{3}$ alloys as expected from the phase diagram Fig. 5(c) ${ }^{(50)-(53)}$. The composition dependence of $\mathrm{M}_{s}$ as well as $\mathrm{A}_{\mathrm{s}}$ or $T_{0}$ is related to the thermodynamic stability of $\mathrm{t}-\mathrm{ZrO}_{2}$. The phase diagrams of Fig. 5 indicate that $\mathrm{t}$ $\mathrm{ZrO}_{2}$ is stabilized rather than $\mathrm{m}-\mathrm{ZrO}_{2}$ by an addition of cubic-stabilizing oxides, and then $\mathbf{M}_{\mathrm{s}}$ temperature lowers by the addition of these oxides.

The $\mathbf{M}_{\mathrm{s}}$ temperature is defined as a fixed temperature for a metallic alloy, which appears at higher cooling rates than a certain critical rate. Whereas the martensitic $t-m$ transformation in zirconia is induced at moderate cooling rates, and rapid cooling usually suppresses the transformation. The $\mathrm{M}_{\mathrm{s}}$ temperature can be decided only for such cooling rates.

Another important fact is that $\mathbf{M}_{\mathrm{s}}$ temperature depends markedly on particle or grain size. It has originally been reported that pure zirconia powders less than about $30 \mathrm{~nm}$ are t$\mathrm{ZrO}_{2}$ at room temperature and do not transform into stable $\mathrm{m}-\mathrm{ZrO}_{2}{ }^{(54)}$. This behavior has been called the size effect. The $\mathrm{t}-\mathrm{ZrO}_{2}$ particles embedded in ceramic matrix are much difficult to transform into $\mathrm{m}-\mathrm{ZrO}_{2}$ than isolated particles so that much larger $\mathrm{t}-\mathrm{ZrO}_{2}$ particles are retained at room temperature $^{(55)-(57)}$.

Figure 10 shows the relation between particle size and $M_{s}$ temperature ${ }^{(3)}$. The $M_{s}$ temperature lowers for smaller-grained $\mathrm{ZrO}_{2}$. It may be said that there is a critical size of $\mathrm{t}-\mathrm{ZrO}_{2}$ grains transformable into $\mathrm{m}-\mathrm{ZrO}_{2}$ at each temperature. Several different interpretations have been given for explaining this size effect $^{(45)(54)(58)-(64)}$. The proposed origins for the size effect are;

(i) the difference in surface or interfacial energies between $\mathrm{m}$ - and $\mathrm{t}-\mathrm{ZrO}_{2}{ }^{(54)(58)(59)}$,

(ii) the localization of strain energy near the particle/matrix interface ${ }^{(45)}$,

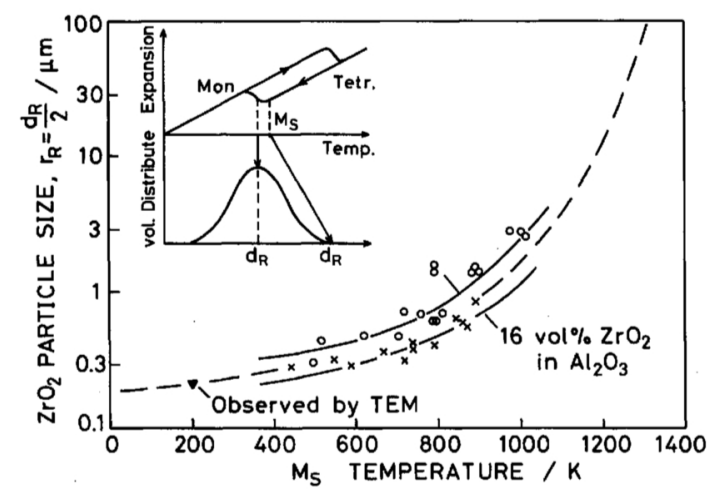

Fig. 10 Particle size dependence of $M_{s}$ temperature of $\mathrm{ZrO}_{2}$ in $\mathrm{Al}_{2} \mathrm{O}_{3}-\mathrm{ZrO}_{2}$ composites ${ }^{(3)}$. 
(iii) the smaller probability of nucleation of martensite embryo in smaller particles ${ }^{(61)}$ and

(iv) the loss of coherency between particle and matrix ${ }^{(62)}$.

The validity of these interpretations has been discussed by inspecting the experimental data $^{(63)}$. The difficulty of martensite nucleation in small particles may be the most probable origin for the size effect ${ }^{(63)}$.

\section{Athermal and isothermal nature}

It has originally been reported that the $t-m$ transformation in zirconia occurs in a certain temperature range, and does not take place isothermally, i.e. the fraction of transformed $\mathrm{m}-\mathrm{ZrO}_{2}$ increases only by lowering temperatures $^{(43)(50)(65)(68)}$. This is the characteristic of athermal transformation. On the contrary, there were some reports on the occurrence of isothermal $\mathrm{t}-\mathrm{m}$ transformation ${ }^{(69)}$. It has later been clarified that the degradation of mechanical properties by low-temperature annealing in $\mathrm{ZrO}_{2}-\mathrm{Y}_{2} \mathrm{O}_{3}$ or $\mathrm{ZrO}_{2}-\mathrm{CeO}_{2}$ alloys is caused by the isothermal $\mathrm{t}-\mathrm{m}$ transformation $^{(30)-(33)(70)}$. The origin of this isothermal transformation has recently been studied by several workers ${ }^{(71)-(78)}$.

Figure 11 shows the increment of $\mathrm{m}-\mathrm{ZrO}_{2}$ during isothermal annealing in $\mathrm{ZrO}_{2}-2.2$ $\mathrm{mol} \% \mathrm{Y}_{2} \mathrm{O}_{3}$ alloy ${ }^{(73)}$. This increase of $\mathrm{m}-\mathrm{ZrO}_{2}$ result from the isothermal $\mathrm{t}-\mathrm{m}$ transformation at these temperatures. The $\mathrm{t}-\mathrm{m}$ transformation occurs most easily around $550 \mathrm{~K}$, and the transformation-start and finish curves are represented by a TTT diagram such as isother-

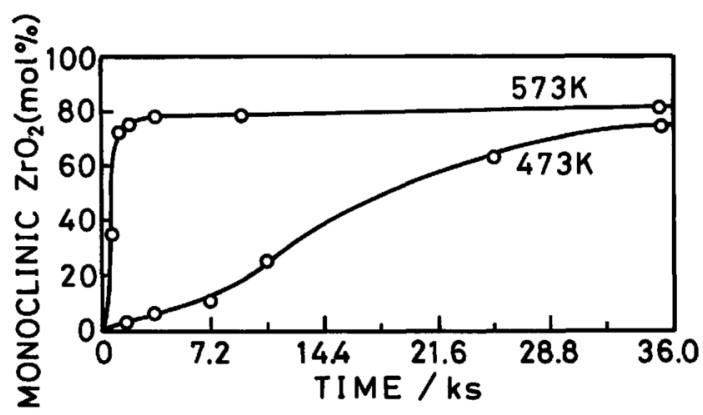

Fig. 11 Change in $\mathrm{m}-\mathrm{ZrO}_{2}$ content with isothermal annealing in $\mathrm{ZrO}_{2}-2.2 \mathrm{~mol} \% \mathrm{Y}_{2} \mathrm{O}_{3}{ }^{(73)}$. mal diffusional reaction or precipitation ${ }^{(73)}$. This fact may indicate that a certain diffusional reaction takes part in the $\mathrm{t}-\mathrm{m}$ transformation. It has also been found that this transformation is very sensitive to the surrounding atmosphere. There is a number of the experimental evidence that the presence of water accelerates the transformation ${ }^{(7)(72)(78)}$. The positive effect of $\mathrm{NH}_{3}$ and alkali metal fluorides as well as water has also been reported $^{(78)(79)}$. The transformation is markedly retarded in vacuum ${ }^{(75)}$. On the basis of these results, it has been proposed that the promotion of the transformation is caused by oxygen itself $^{(75)}$ or $\mathrm{OH}^{-}$ion $^{(71)(73)(76)(77)}$ or $\mathrm{Y}(\mathrm{OH})_{3}{ }^{(72)(74)}$. The formation of $\mathrm{OH}^{-}$ions may be most probable, because these ions are identified in isothermally-transformed alloys by infrared absorption spectra or Raman spectra ${ }^{(76)(77)}$. The $\mathrm{Zr}-\mathrm{O}-\mathrm{H}$ bonds formed by the diffusion of $\mathrm{OH}^{-}$ions may be effective to induce the transformation $^{(71)(77)}$.

\section{The Diffusionless Cubic-to-Tetragonal Transformation}

The cubic-to-tetragonal (c-t) transformation was first found by Smith and Cline ${ }^{(80)}$, which was reconfirmed by several workers ${ }^{(42)(81)}$. From detailed metallographic examinations in $\mathrm{ZrO}_{2}-$ $\mathrm{UO}_{2}$ alloys, Cohen and Schaner have suggested that the diffusionless c-t transformation is of martensitic type ${ }^{(82)}$. Andersson and Gupta have argued that the martensitic $\mathrm{c}-\mathrm{t}$ transformation can be predicted in $\mathrm{ZrO}_{2}-\mathrm{Y}_{2} \mathrm{O}_{3}$ alloys from its phase diagram of Fig. 5(c) ${ }^{(61)}$. Andersson et al. have found the generation of $\mathrm{t}^{\prime}-\mathrm{ZrO}_{2}$ plates in $\mathrm{ZrO}_{2}-4.5 \mathrm{~mol} \% \quad \mathrm{Y}_{2} \mathrm{O}_{3}$ alloy fairly rapidly cooled from $2300 \mathrm{~K}$ to room temperature ${ }^{(83)}$. Plates or lenticular features of $\mathrm{t}^{\prime}-\mathrm{ZrO}_{2}$ are commonly found in $\mathrm{ZrO}_{2}-\mathrm{Y}_{2} \mathrm{O}_{3}$ alloys rapidly-cooled from single cubic phase region ${ }^{(24)(62)(84)}$. Figure 12 is an example of lenticular $\mathrm{t}^{\prime}-\mathrm{ZrO}_{2}$ in a $\mathrm{ZrO}_{2}-7 \mathrm{~mol} \% \mathrm{Y}_{2} \mathrm{O}_{3}$ alloy, which was waterquenched from $1973 \mathrm{~K}^{(84)}$. Large lenticular features accompanying a small number of dislocations are clearly seen in Fig. 12. The longitudinal direction of the lenticular features is nearly parallel to the $\{011\}_{\mathrm{t}}$ plane. Microstructures of $\mathrm{t}^{\prime}-\mathrm{ZrO}_{2}$ formed by the diffu- 


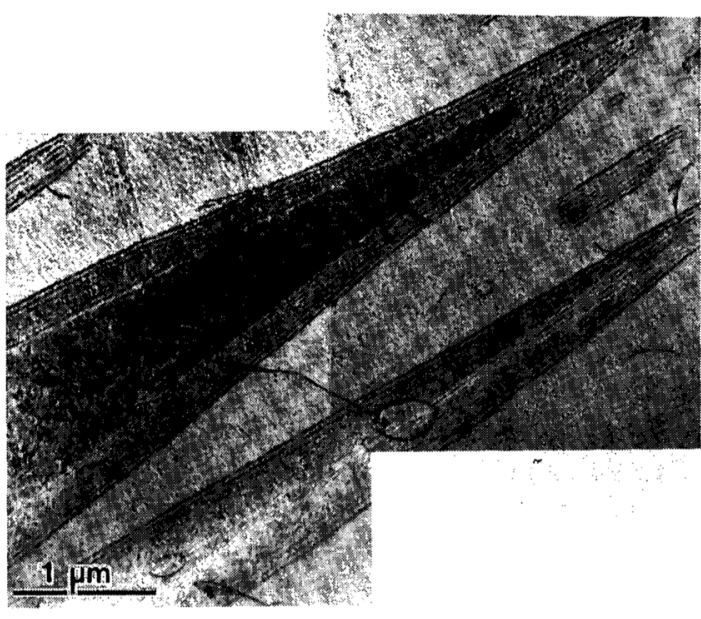

Fig. 12 Microstructure of $\mathrm{ZrO}_{2}-7.1 \mathrm{~mol} \% \quad \mathrm{Y}_{2} \mathrm{O}_{3}$ alloy water-quenched from $1973 \mathrm{~K}^{(84)}$.

sionless c-t transformation resemble those of martensite in some metallic alloys. If one examines these microstructural features by conventional bright field images of electron microscopy, it appears well established that the diffusionless $c-t$ transformation is of the martensitic type. However, a very important information has first been obtained by Heuer and his colleagues ${ }^{(85)-(87)}$. They have found that curvilinear features showing the antiphase domain boundary (APB)-like contrast are observed in dark field image taken by a reflection of the type odd, odd, even, which is forbidden for the fluorite structure.

Figure 13 is an example of such images in a $\mathrm{ZrO}_{2}-3 \mathrm{~mol} \% \mathrm{Y}_{2} \mathrm{O}_{3}$ alloy ${ }^{(8)}$. The microstructure consists of small domains separated by curved boundaries with APB-like contrast. The displacement vector along the boundary is proposed to be either $a / 2[101]$ or $a / 2[011]^{(85)(88)}$. The ionic array across the boundary with this displacement vector is drawn in Fig. 14, which is a view from the [001] direction. Oxygen ions depicted as filled and hatched circles are displaced slightly in the [001] and [001] directions from their original positions in the cubic fluorite structure as shown in Fig. 2. Oxygen ions in nearest neighbors are mutually displaced in opposite directions in each domain, but the periodicity of the oxygen ion array is not kept across the boundary; oxygen ions dis-

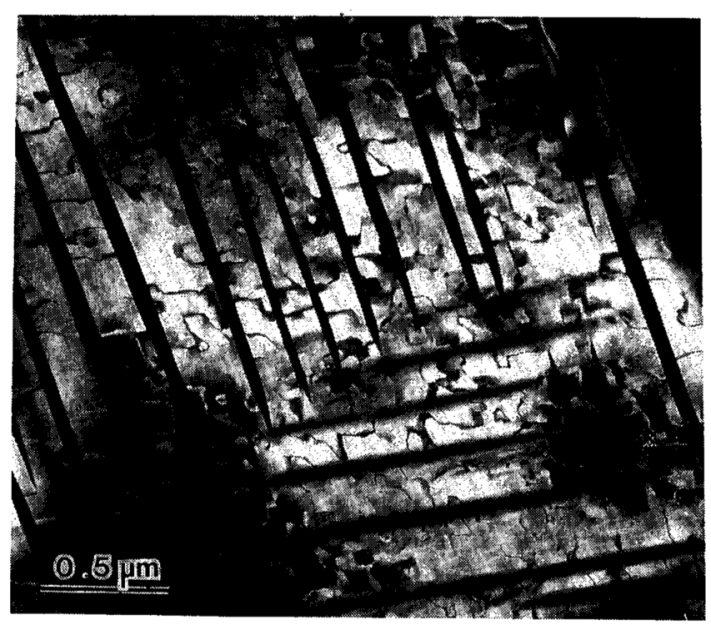

Fig. 13 The domain structure in $\mathrm{ZrO}_{2}-3 \mathrm{~mol} \% \mathrm{Y}_{2} \mathrm{O}_{3}$ alloy taken by a 112 reflection $^{(8)}$.

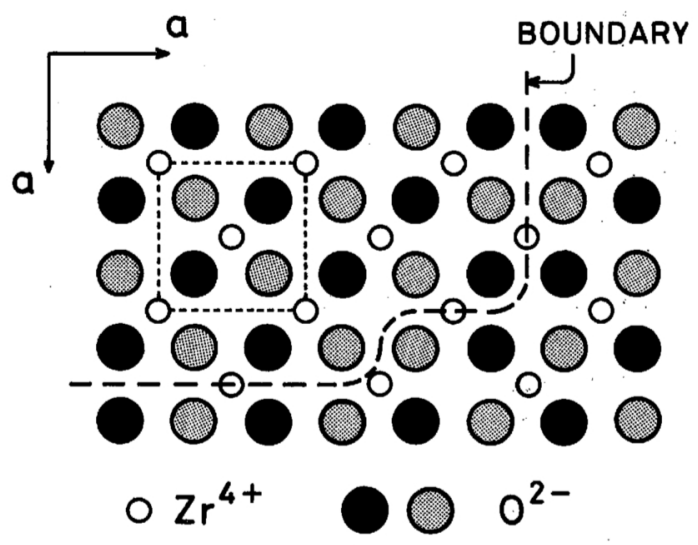

Fig. 14 Ionic array near the domain boundary viewed from [001]. Small open circles represent cations on a (001) plane, while large filled and hatched ones are oxygen ions about $c / 4$ below the (001) plane ${ }^{(8)}$.

placed in the same direction are face to face along the boundary. This situation is the same with that of the atomic array along APB in ordered alloys.

The results mentioned above indicate that a variety of microstructures is formed by the diffusionless c-t transformation. It has been pointed out that these microstructures resembles those of martensite in $\mathrm{Ti}-\mathrm{Ni}-\mathrm{Fe}$ shape memory alloys ${ }^{(89)}$. In these alloys, the domains with APB's-like contrast and needle domains, which are very similar to the domains 
and lenticular $\mathrm{t}^{\prime}-\mathrm{ZrO}_{2}$ in $\mathrm{ZrO}_{2}-\mathrm{Y}_{2} \mathrm{O}_{3}$ alloys, appear as premartensitic phases prior to the final martensite products. The premartensitic effect has been detected by electrical resistivity anomaly ${ }^{(90)(91)}$ and streaks or extra spots in electron diffraction patterns ${ }^{(90)(92)(93)}$, which are correlated with the generation of domain structures. Despite of the microstructural similarities, there is a fundamental difference between the microstructure formed by the diffusionless $\mathrm{c}$ - $\mathrm{t}$ transformation in $\mathrm{ZrO}_{2}-\mathrm{Y}_{2} \mathrm{O}_{3}$ alloys and that of premartensite in $\mathrm{Ti}-\mathrm{Ni}-\mathrm{Fe}$ alloys. In $\mathrm{Ti}-\mathrm{Ni}-\mathrm{Fe}$ alloys, the domain structures are imaged by $1 / 3(111)$ or $1 / 3(110)$ type superlattice reflections, which is the characteristic of the premartensitic phase but not from the final product phase. On the other hand, the domain structure in $\mathrm{ZrO}_{2}-\mathrm{Y}_{2} \mathrm{O}_{3}$ alloys is revealed by a 112 reflection, which is believed to originate from the oxygen ion displacement of the tetragonal phase from the cubic fluorite structure. This fact seems to indicate that the domain structure itself is the characteristic of $\mathrm{t}^{\prime}-\mathrm{ZrO}_{2}{ }^{(8)}$. The domain structure of $\mathrm{t}^{\prime}-\mathrm{ZrO}_{2}$ has the following features;

(i) The domains are always formed over the entire region of the sample ${ }^{(85)(94)}$. This is valid not only in a region of single $\mathrm{t}^{\prime}-\mathrm{ZrO}_{2}$ variant, but also of two or three variants.

(ii) The domains seem to be formed prior to thin-plates or lenticular features ${ }^{(94)}$.

(iii) The domain size decreases with an increase of alloy content ${ }^{(94)}$.

(iv) The domains grow very heterogeneously by low-temperature annealing ${ }^{(8)}$

Among these features, the first and second ones are particularly important for understanding the nature of the diffusionless c-t transformation. Since the domain structure of $\mathrm{t}^{\prime}-\mathrm{ZrO}_{2}$ is initially formed over the whole region of the sample, this transformation has the nature which always goes to completion as first pointed out by the Heuer's group ${ }^{(86)-(88)}$. This nature is completely different from that of martensitic transformation, and is the second order phase transition ${ }^{(95)}$. It has been pointed out that this transformation is similar to the order-disorder transition in $\beta$-brass, in which ordered domains of the $\beta^{\prime}$-phase are inevitably developed throughout the sample during cool- ing from the high-temperature disordered $\beta$ phase. In other words, the order-disorder transition is always completed during cooling, and the mixed structure of $\beta$ and $\beta^{\prime}$ is never developed. This transition is accepted to be the second order phase transition which is induced by the continuous change in the long-range order parameter around the transition temperature ${ }^{(95)}$. The diffusionless $\mathrm{c}-\mathrm{t}$ transformation accompanying the domain structure in $\mathrm{ZrO}_{2-}$ $\mathrm{Y}_{2} \mathrm{O}_{3}$ alloys has a similar nature to the orderdisorder transition in $\beta$-brass. It is quite surprising that the diffusionless $c-t$ transformation is the transition of the second order type. How to explain this fact? This behavior may originate from the continuous lattice parameter change from $\mathrm{c}-\mathrm{ZrO}_{2}$ to $\mathrm{t}^{\prime}-\mathrm{ZrO}_{2}$ at the transformation temperature. Otherwise, the transformation occurs in a manner of the first order phase transition, which is generally characterized by the discontinuous lattice parameter change by the transformation. It may be too optimistic to conclude from Fig. 4 that the lattice parameter changes continuously from $\mathrm{c}-\mathrm{ZrO}_{2}$ to $\mathrm{t}-\mathrm{ZrO}_{2}$ in pure zirconia. Accurate lattice parameter measurements are very difficult for pure zirconia because of its high transformation temperature. In zirconia alloys, the lattice parameter measurements associated with the diffusionless c-t transformation is usually made impossible by the diffusional reaction. It is, therefore, only possible to point out here that the diffusionless $c-t$ transformation in $\mathrm{ZrO}_{2}-\mathrm{Y}_{2} \mathrm{O}_{3}$ alloys is likely to have a nature of the second order phase transition.

Someone may insist that the second order type transition cannot be predicted from the $\mathrm{ZrO}_{2}-\mathrm{Y}_{2} \mathrm{O}_{3}$ phase diagram in Fig. 5(c). However, it has later been found that the hightemperature equilibrium between $\mathrm{t}-\mathrm{ZrO}_{2}$ and c- $\mathrm{ZrO}_{2}$ is different from that of Fig. 5(c), and $\mathrm{t}-\mathrm{ZrO}_{2}$ has a retrograde solubility at high temperatures ${ }^{(96)}$. This point is discussed again in the next section.

Finally, it is necessary to discuss the origin of thin-plates or lenticular features of $\mathrm{t}^{\prime}-\mathrm{ZrO}_{2}$. These features are essentially $\mathrm{t}^{\prime}-\mathrm{ZrO}_{2}$ variants, some of which are twin-oriented. The initial development of domain structure in a coarse t- 
$\mathrm{ZrO}_{2}$ variant will induce the strain energy which increases with an increase of tetragonality. Generation of two or three $\mathrm{t}^{\prime}-\mathrm{ZrO}_{2}$ variants is probably effective in relieving such a strain energy. It is well-known that the thin-plates or lenticular features are the morphologies for effectively relielving the strain energy in solids. This fact may be the reason why the thin-plates or lenticular features are commonly formed as $\mathrm{t}^{\prime}-\mathrm{ZrO}_{2}$ variants.

\section{The Diffusional Cubic-Tetragonal Phase Separation and Precipitation}

The precipitation of $\mathrm{t}-\mathrm{ZrO}_{2}$ from supersaturated $\mathrm{c}-\mathrm{ZrO}_{2}$ solid solutions has extensively been examined ${ }^{(97)-(104)}$. The morphology of $\mathrm{t}-\mathrm{ZrO}_{2}$ precipitates varies with the type of alloys, aging temperature and time, and so on. In $\mathrm{ZrO}_{2}-\mathrm{MgO}$, small spherical or disc-shaped precipitates are formed initially ${ }^{(100)}$, which grow into the ellipsoidal-shaped ones ${ }^{(98)-(100)}$. Various precipitate morphologies from cuboids and rectangular plates to irregular equiaxed forms are found in $\mathrm{ZrO}_{2}-\mathrm{CaO}^{(98)}$. The plate-shaped $\mathrm{t}-\mathrm{ZrO}_{2}$ precipitates are often observed in $\mathrm{ZrO}_{2}-\mathrm{Y}_{2} \mathrm{O}_{3}{ }^{\left({ }^{(9)}\right)(103)}$, an example of which is shown in Fig. 15 ${ }^{(103)}$. The difference in precipitate morphology may result from that in misfit between $\mathrm{c}-\mathrm{ZrO}_{2}$ and $\mathrm{t}-\mathrm{ZrO}_{2}{ }^{(98)}$. The cube-cube orientation relationship is satisfied between these two phases ${ }^{(97)(101)(104)}$. The $\mathrm{t}-\mathrm{ZrO}_{2}$

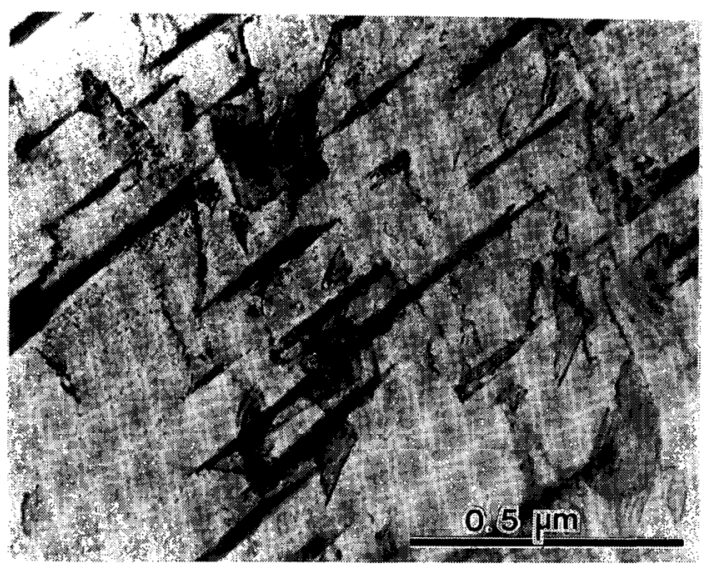

Fig. 15 Plate-shaped $\mathrm{t}-\mathrm{ZrO}_{2}$ precipitates in $\mathrm{c}-\mathrm{ZrO}_{2}$ matrix in $\mathrm{ZrO}-5.2 \mathrm{~mol} \% \mathrm{Y}_{2} \mathrm{O}_{3}$ alloy aged at $1973 \mathrm{~K}$ for 3.6 $\mathrm{ks}^{(103)}$. precipitates are sometimes twinned ${ }^{(85)(97)(104)}$, which may be related to the colony structure in PSZ $^{(85)}$.

In addition to $\mathrm{t}-\mathrm{ZrO}_{2}$ precipitates, metastable phases sometimes appear during aging or subsequent cooling. For example, the $\delta$-phase $\left(\mathrm{Mg}_{2} \mathrm{Zr}_{5} \mathrm{O}_{12}\right)^{(100)}$ or the $\beta$-phase $\left(\mathrm{Mg}_{2} \mathrm{Zr}_{5} \mathrm{O}_{12}\right)^{(102)}$ is generated in $\mathrm{ZrO}_{2}-\mathrm{MgO}$, and the $\phi_{1}$-phase $\left(\mathrm{CaZr}_{4} \mathrm{O}_{9}\right)$ in $\mathrm{ZrO}_{2}-\mathrm{CaO}^{(101)}$. Furthermore, a eutectoid reaction such as

$$
\mathrm{c}-\mathrm{ZrO}_{2} \longrightarrow \mathrm{t}-\mathrm{ZrO}_{2}+\mathrm{MgO}
$$

or

$$
\mathrm{c}-\mathrm{ZrO}_{2} \longrightarrow \mathrm{m}-\mathrm{ZrO}_{2}+\mathrm{MgO}
$$

may take place during cooling ${ }^{(85)(99)}$. Therefore, the microstructures formed by heat treatment of PSZ often become very complicated ones.

In the rest of this section, an early stage of the phase separation between $\mathrm{c}-\mathrm{ZrO}_{2}$ and $\mathrm{t}$ $\mathrm{ZrO}_{2}$ is discussed. Microstructural features different from usual precipitation structure have been found in early stages of isothermal aging in the $\mathrm{c}-\mathrm{ZrO}_{2} / \mathrm{t}-\mathrm{ZrO}_{2}$ two-phase region of $\mathrm{ZrO}_{2}-\mathrm{Y}_{2} \mathrm{O}_{3}$ alloys ${ }^{(103)(105)}$. Figure 16 shows the microstructure of a $\mathrm{ZrO}_{2}-4 \mathrm{~mol} \% \quad \mathrm{Y}_{2} \mathrm{O}_{3}$ alloy isothermally-aged at $1973 \mathrm{~K}$ for $600 \mathrm{~s}^{(105)}$. This micrograph was taken in a beam direction close to [011]. Bright and dark lamellae are developed in two directions nearly normal to $\langle 111\rangle$, which are included in the (011) plane. Satellite-like reflections appear in the $\langle 111\rangle$ directions. It is to be noted that the $\langle 111\rangle$ direction is elastically-soft in $\mathrm{c}-\mathrm{ZrO}_{2}{ }^{(106)}$. This type of microstructure has been found in early stages of isothermal aging of alloys with a certain composition range ${ }^{(105)}$, which is followed by precipitation of ellipsoidal $\mathrm{t}-\mathrm{ZrO}_{2}$ in the matrix $^{(103)}$. The present author's group has referred to the microstructure, Fig. 16, as the modulated structure, because this microstructure has the characteristic features of spinodally-decomposed alloys ${ }^{(103)(105)}$. Heuer and his coworkers have insisted that this type of microstructure is the tweed structure whose contrast is generated by strain field of fine and coherent $\mathrm{t}-\mathrm{ZrO}_{2}$ precipitates in the $\mathrm{c}-\mathrm{ZrO}_{2}$ matrix $^{(107)(108)}$. According to their experimental results, the tweed striation runs normal to $\langle 101\rangle$, and not to $\langle 111\rangle^{(108)}$. The difference in 


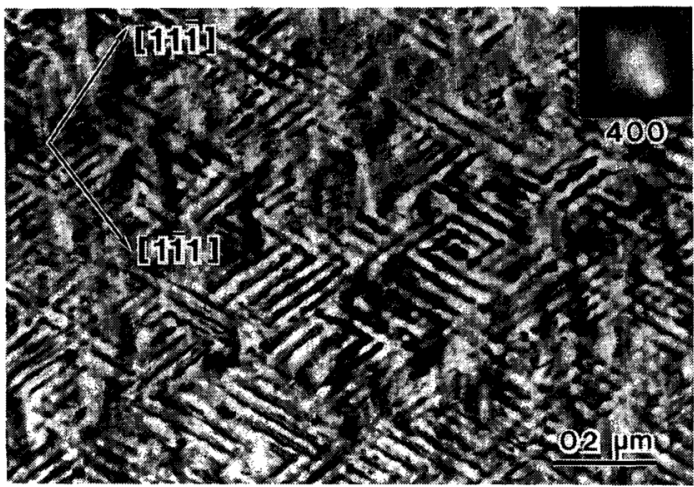

Fig. 16 The modulated structure in $\mathrm{ZrO}_{2}-4 \mathrm{~mol} \% \mathrm{Y}_{2} \mathrm{O}_{3}$ alloy aged at $1973 \mathrm{~K}$ for $600 \mathrm{~s}^{(105)}$. The beam direction is close to [011].

the normal direction of bright and dark lamellae between the "modulated" and "tweed" microstructures may reflect the different microstructural origin. They have also insisted that it is impossible to predict the spinodal decomposition in $\mathrm{ZrO}_{2}-\mathrm{Y}_{2} \mathrm{O}_{3}$ alloys from the cubic/tetragonal equilibrium of Fig. $5(c)^{(108)}$. However, such an argument neglects the following important facts. First of all, the spinodal decomposition does not necessarily take place between two equilibrium phases. There is a number of examples of spinodal decomposition inside metastable binodal in glass systems ${ }^{(109)}$. Second, the author has pointed out that the spinodal-like phase separation may occur in $\mathrm{ZrO}_{2}-\mathrm{Y}_{2} \mathrm{O}_{3}$, provided that the lattice parameter change occurs continuously from $\mathrm{c}-\mathrm{ZrO}_{2}$, to $\mathrm{t}-\mathrm{ZrO}_{2}{ }^{(110)}$. Figure 17 shows a plot of the lattice parameter of $\mathrm{t}-\mathrm{ZrO}_{2}$ and $\mathrm{c}-\mathrm{ZrO}_{2}$ as a function of $\mathrm{Y}_{2} \mathrm{O}_{3}$ content ${ }^{(19)(111)}$. The tetragonality of $\mathrm{t}-\mathrm{ZrO}_{2}$ decreases with an increase of $\mathrm{Y}_{2} \mathrm{O}_{3}$ content, and the lattice parameter at zero tetragonality of $t-\mathrm{ZrO}_{2}$ is very close to that of $\mathrm{c}-\mathrm{ZrO}_{2}$. Although the lattice parameter measurements by X-ray diffraction is not so accurate to strictly check the continuous lattice parameter change from $\mathrm{c}-\mathrm{ZrO}_{2}$ to $\mathrm{t}-\mathrm{ZrO}_{2}$ even at room temperature, the data of Fig. 17 seems to support the lattice parameter continuity between $\mathrm{c}-\mathrm{ZrO}_{2}$ and $\mathrm{t}$ $\mathrm{ZrO}_{2}$. This fact may also be related to the anormal phase equilibrium between these phases as mentioned before.

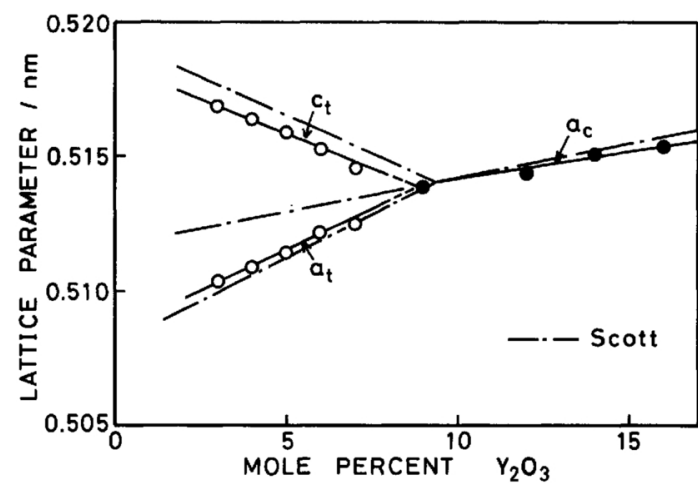

Fig. 17 Change in lattice parameter of $\mathrm{t}-\mathrm{ZrO}_{2}$ and $\mathrm{c}-\mathrm{ZrO}_{2}$ with yttria content ${ }^{(8)}$.

Figure 18 shows the compiled data on the cubic/tetragonal equilibrium and a possible construction of free energy-composition $(G-x)$ diagram $^{(112)}$. Note that the $G-x$ diagram in Fig. 18 is different from that drawn by several workers ${ }^{(61)(85)}$. It seems reasonable that the $\mathrm{t}-\mathrm{ZrO}_{2}$ can take various tetragonalities, but the $\mathrm{t}-\mathrm{ZrO}_{2}$ with a specified tetragonality takes a minimum free energy at a certain temperature in each $\mathrm{ZrO}_{2}-\mathrm{Y}_{2} \mathrm{O}_{3}$, alloy. The $G-x$ diagram for t- $\mathrm{ZrO}_{2}$ in Fig. 18 is a locus of such minimum free energy for each composition. On this locus, the tetragonality decreases with an increase of $\mathrm{Y}_{2} \mathrm{O}_{3}$ content and finally becomes zero at a certain composition. If the free energy of $\mathrm{c}-\mathrm{ZrO}_{2}$ at this composition is the same as that of $\mathrm{t}-\mathrm{ZrO}_{2}$ with zero tetragonality, then the $G-x$ diagram will be such as Fig. 18, while if a certain energy gap exists between $\mathrm{c}-\mathrm{ZrO}_{2}$ and $\mathrm{t}-\mathrm{ZrO}_{2}$ with zero tetragonality at this same composition, the $G-x$ diagrams for $\mathrm{c}-\mathrm{ZrO}_{2}$ and $\mathrm{t}-\mathrm{ZrO}_{2}$ will be different ones. In the latter case, a discontinuity usually appears in lattice parameter of $t$ $\mathrm{ZrO}_{2}$ and $\mathrm{c}-\mathrm{ZrO}_{2}$, and the phase transformation and precipitation occur in a manner of first order phase transition. However, as described in Section VI, the diffusionless c-t transformation is of second order type. This fact also suggests the continuous lattice parameter change from $\mathrm{c}-\mathrm{ZrO}_{2}$ to $\mathrm{t}-\mathrm{ZrO}_{2}$, and there is no energy gap between $\mathrm{c}-\mathrm{ZrO}_{2}$ and $\mathrm{t}-\mathrm{ZrO}_{2}$ with zero tetragonality at the same composition. This must also be an origin of spinodal-like phase 

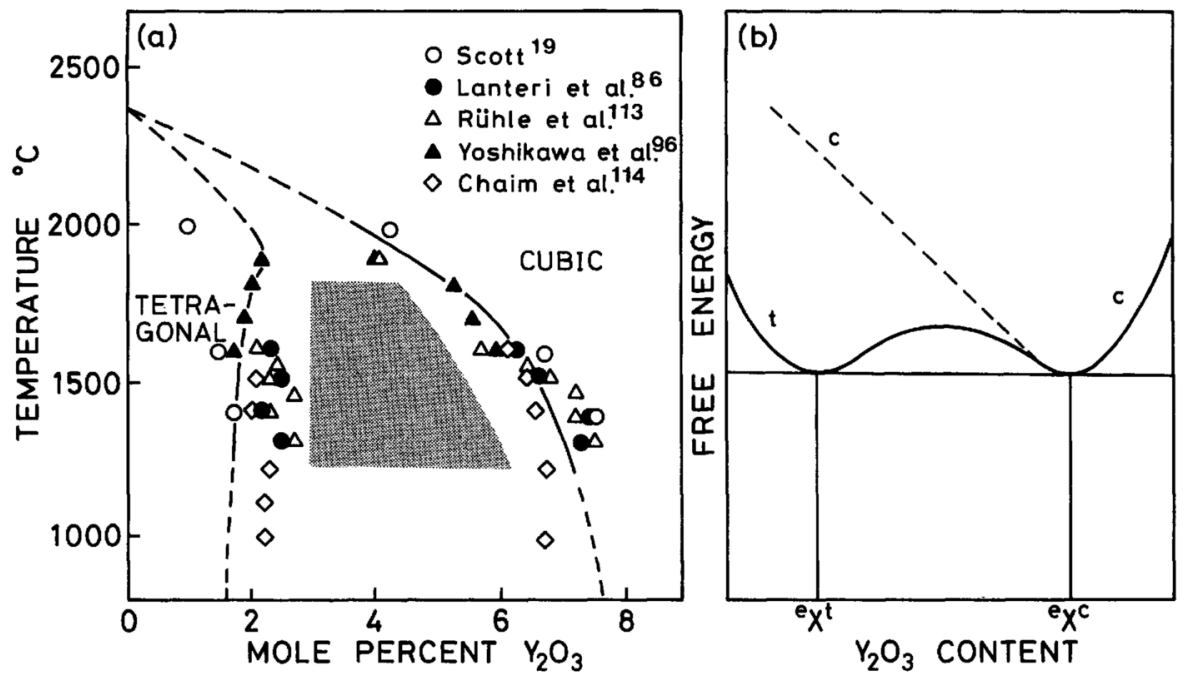

Fig. 18 Cubic-tetragonal equilibrium and proposed $G-x$ diagram at a certain temperature. The compositions ${ }^{\mathrm{e}} x^{\mathrm{t}}$ and ${ }^{\mathrm{e}} x^{\mathrm{c}}$ are the equilibrium yttria content in $\mathrm{t}-$ and $\mathrm{c}-\mathrm{ZrO}_{2}$. The hatched area is the region where the modulated structure was found by isothermal aging ${ }^{(112)}$.

separation between these phases by diffusional reaction.

\section{Conclusion}

A variety of microstructures is formed during sintering and heat treatment of PSZ at high temperatures. The tetragonal-to-monoclinic and cubic-to-tetragonal phase transformations are relevant to these microstructures. The diffusionless $\mathrm{t}-\mathrm{m}$ transformation is of martensitic type, which accompanies twins or dislocations in product phase. The diffusionless c-t transformation results in, at least, two different microstructural features. One is the domain structure revealed in dark field image taken by a reflection of the type, odd, odd, even, which is forbidden for cubic fluorite structure. The other is the thin-plates or lenticular features found in coventional bright field image in electron microscopy. Generation of the domain structure seems to occur initially during the diffusionless $\mathrm{c}-\mathrm{t}$ transformation, which is followed by the formation of thin plates or lenticular features. The domain structure of $t^{\prime}$ $\mathrm{ZrO}_{2}$ always appear over the whole region of the sample. This fact means that the diffusionless c-t transformation is always com- pleted, and has a nature of the second order phase transition. Thin plates or lenticular features are regarded to be $\mathrm{t}^{\prime}-\mathrm{ZrO}_{2}$ variants, which are probably induced for accommodating the transformation strain. The precipitation structure of $\mathrm{t}-\mathrm{ZrO}_{2}$ in $\mathrm{c}-\mathrm{ZrO}_{2}$ matrix is commonly observed in alloys heattreated in the cubic/tetragonal two-phase region. In addition to the conventional precipitation structure, the modulated structure is developed in early stages of aging in this two-phase region in $\mathrm{ZrO}_{2}-\mathrm{Y}_{2} \mathrm{O}_{3}$ alloys. The modulated structure has the characteristic features of spinodally-decomposed alloys. The nature of the diffusionless $c-t$ transformation, and also the diffusional c-t phase separation in $\mathrm{ZrO}_{2}-\mathrm{Y}_{2} \mathrm{O}_{3}$ alloys can be interpreted by assuming that there is no transient energy barrier from $\mathrm{c}-\mathrm{ZrO}_{2}$ to $\mathrm{t}-\mathrm{ZrO}_{2}$ with zero tetragonality. This assumption may be supported by the fact that the lattice parameter is likely to change continuously from $\mathrm{c}-\mathrm{ZrO}_{2}$ to $\mathrm{t}-\mathrm{ZrO}_{2}$.

\section{Acknowledgment}

This work was financially supported by Grant-in-Aid Shiken-kenkyu (2) 62850132 for Fundamental Research from the Ministry of Education, Science and Culture, Japan. 


\section{REFERENCES}

(1) R. C. Garvie, R. H. Hannink and R. T. Pascoe: Nature, 258 (1975), 703.

(2) A. G. Evans and A. H. Heuer: J. Am. Ceram. Soc., 63 (1981), 241.

(3) N. Claussen and M. Rühle: Advances in Ceramics, Vol. 3, Science and Technology of Zirconia, ed. by A. H. Heuer and L. W. Hobbs, The Am. Ceram. Soc., OH, (1981), p. 137.

(4) R. M. McMeeking and A. G. Evans: J. Am. Ceram. Soc., 65 (1982), 242.

(5) A. G. Evans: Advances in Ceramics, Vol. 12, Science and Technology of Zirconia II, ed. by N. Claussen, M. Rühle and A. H. Heuer, The Am. Ceram. Soc., OH, (1984), p. 193.

(6) N. Claussen: Ref. (5), p. 325.

(7) A. G. Evans and R. M. Cannon: Acta Metall., 34 (1986), 761.

(8) T. Sakuma: A paper presented at MRS Meeting, Tokyo, (1988).

(9) E. P. Butler: Mater. Sci. Tech., 1 (1985), 417.

(10) R. Stevens: Zirconia and Zirconia Ceramics, ed. by Magnesium Elektron Ltd. (1986).

(11) D. K. Smith and C. F. Cline: quoted by D. Viechnicki and V. S. Stubican: J. Am. Ceram. Soc., 48 (1965), 292.

(12) G. Teufer: Acta Cryst., 15 (1962), 1187.

(13) J. Faber, Jr. and M. H. Mueller: Phys. Rev., B17 (1978), 4884.

(14) D. K. Smith and H. W. Newkirk: Acta Cryst., 18 (1965), 983.

(15) R. N. Patil and E. C. Subbarao: J. Appl. Cryst., 2 (1969), 281.

(16) P. Aldebert and J-P. Traverse: J. Am. Ceram. Soc., 68 (1985), 34

(17) V. S. Stubican and S. P. Ray: ibid., 60 (1977), 534.

(18) C. F. Grain: ibid., 50 (1967), 288.

(19) H. G. Scott: J. Mater. Sci., 10 (1975), 1527.

(20) E. Tani, M. Yoshimura and S. Somiya: J. Am. Ceram. Soc., 66 (1983), 506.

(21) R. P. Ingel, D. Lewis, B. A. Bender and R. W. Rice: Ref. (5), p. 408.

(22) T. Masaki: J. Am. Ceram. Soc., 69 (1986), 519.

(23) K. Tsukuma, Y. Kubota and K. Nobugai: Yogyokyokaishi, 92 (1984), 233.

(24) T. Sakuma, Y. Yoshizawa and H. Suto: J. Mater. Sci., 20 (1985), 2399.

(25) T. Sakuma, H. Eda and H. Suto: Advances in Ceramics, Vol. 24, Science and Technology of Zirconia III, in press.

(26) K. Tsukuma and M. Shimada: J. Mater. Sci., 20 (1985), 1178.

(27) H. Eda, T. Sakuma and H. Suto: J. Japan Inst. Metals, 51 (1987), 965.

(28) R. A. Miller, J. L. Smialek and R. G. Garlick: Ref. (3), p. 241.

(29) T. Masaki: Inst. J. High Tech. Ceram., 2 (1986), 85.

(30) K. Kobayashi, H. Kuwajima and T. Masaki: Sol.
State Ionics, $3 / 4$ (1981), 489.

(31) M. Matsui, T. Soma and I. Oda: Ref. (5), p. 371.

(32) W. Watanabe, S. Iio and I. Fukuura: Ref. (5), p. 391.

(33) T. Sato, S. Ohtani and M. Shimada: J. Mater. Sci., 20 (1985), 1466.

(34) A. A. Griffith: Phil. Trans. Roy. Soc., 221 (1920), 163.

(35) M. V. Swain: Acta Metall., 33 (1985), 2083.

(36) R. C. Garvie, R. R. Hughan and R. T. Pascoe: Mater. Sci. Res., (1978), p. 263.

(37) D. L. Porter and A. H. Heuer: J. Am. Ceram. Soc., 62 (1979), 298.

(38) R. H. J. Hannink: J. Mater. Sci., 18 (1983), 457.

(39) T. Masaki, K. Nakajima and K. Shinjo: J. Mater. Sci. Lett., 8 (1986), 1115.

(40) E. C. Subbarao, H. S. Maiti and K. K. Srivastava: Phys. Status Solidi, (a) 21 (1974), 9.

(41) M. J. Bueger: Phase Transformation in Solids, ed. by J. E. Mayer and W. A. Weyl: John Wiley \& Sons, N.Y., (1951), p. 183.

(42) G. M. Wolten: J. Am. Ceram. Soc., 46 (1963), 418.

(43) L. L. Fehrenbacher and L. A. Jacobson: J. Am. Ceram. Soc., 48 (1965), 157.

(44) G. K. Bansal and A. H. Heuer: Acta Metall., 20 (1972), 1281.

(45) A. G. Evans, N. Burlingame, M. Drory and W. M. Krieven: Acta Metall., 29 (1981), 447.

(46) J. E. Bailey: Proc. Roy. Soc., 279A (1964), 395.

(47) G. M. Wolten: Acta Cryst., 17 (1964), 763.

(48) R. N. Patil and E. C. Subbarao: ibid., 26A (1970), 535.

(49) M. Hayakawa, N. Kuntani and M. Oka: A paper presented at MRS meeting, Tokyo (1988).

(50) R. Ruh and H. J. Garrett: Thermal Analysis, Vol. 2, ed. by R. F. Schwinker, Jr. and P. D. Garn, Academic Press, N.Y., (1969), p. 851.

(51) C. Pascual and P. Duran: J. Am. Ceram. Soc., 66 (1983), 23.

(52) R. Ruh, K. S. Mazdiyasni, P. G. Valentine and H. O. Bielstein: J. Am. Ceram. Soc., 67 (1984), C-190.

(53) N. Yoshikawa and H. Suto: J. Japan Inst. Metals, 50 (1986), 108.

(54) R. C. Garvie: J. Phys. Chem., 69 (1965), 1238.

(55) N. Claussen and J. Jahn: Ber. Deu. Kev. Ges., 55 (1978), 98.

(56) A. G. Evans and A. H. Heuer: J. Am. Ceram. Soc., 63 (1980), 241.

(57) R. H. J. Hannink, K. A. Johnston, R. T. Pascoe and R. C. Garvie: Ref. (3), p. 116.

(58) R. C. Garvie: J. Phys. Chem., 82 (1978), 218.

(59) F. F. Lange and D. J. Green: Ref. (3), p. 217.

(60) F. F. Lange: J. Mater. Sci., 17 (1982), 225.

(61) C. A. Andersson and T. K. Gupta: Ref. (3), p. 184.

(62) R. H. J. Hannink: J. Mater. Sci., 13 (1978), 2487.

(63) A. H. Heuer, N. Claussen, W. K. Kriven and M. Rühle: J. Am. Ceram. Soc., 65 (1982), 642.

(64) I-W. Chen and Y-H. Chiao: Acta Metall., 31 (1983), 1627. 
(65) R. F. Geller and P. J. Yavorsky: J. Res. Nat. Bur. Standards, 35 (1945), 87.

(66) A. Dietzel and H. Tober: Ber. Dtsch. Keram. Ges., 30 (1953), 47, 71.

(67) G. M. Wolten: J. Am. Chem. Soc., 80 (1958), 4772.

(68) G. M. Wolten: ibid., 46 (1963), 418.

(69) B. YA. Sukharevskii and I. I. Vishnevskii: Dokl. Akad. Nauk SSSR, 147 (1962), 882.

(70) T. Sato and M. Shimada: Am. Ceram. Soc. Bull., 64 (1985), 1382.

(71) T. Sato and M. Shimada: J. Am. Ceram. Soc., 68 (1985), 356.

(72) F. F. Lange, G. L. Dunlop and B. I. Davies: ibid., 69 (1986), 237.

(73) N. Nakanishi, T. Shigematsu, T. Sugimura and H. Okinaka: J. Jpn. Soc. Powder and Powder Metall., 33 (1986), 356.

(74) H. Schubert: Zirconia Ceramics, 7 (1986), 65.

(75) H. Saka, K. Kuroda, S. Iio, S. Watanabe and T. Imura: Zirconia Ceramics, 8 (1986), 63.

(76) T. Shigematsu and N. Nakanishi: ibid., 9 (1987), 63.

(77) M. Yoshimura, T. Noma, K. Kawabata and S. Somiya: ibid., 8 (1986), 63.

(78) N. Narita, S. Leng, T. Inada and K. Higashita: A paper presented at '87 Int. Symp. and Exhibition on Science and Technology of Sintering, Tokyo (1987).

(79) T. Mori et al.: Yogyo-kyokaishi, 94 (1986), 961.

(80) D. K. Smith and C. F. Cline: J. Am. Ceram. Soc., 45 (1962), 249.

(81) A. G. Boganov, V. S. Rudenko and L. P. Makarov: Dokl. Akad. Nauk SSSR, 160 (1965), 1065.

(82) I. Cohen and B. E. Schaner: J. Nuclear Mater., 9 (1963), 18

(83) C. A. Andersson, J. Greggi, Jr. and T. K. Gupta: Ref. (5), p. 78.

(84) T. Sakuma, H. Eda and H. Suto: Proc. Int. Conf. on Martensitic Transformations, The Japan Inst. Metals, (1986), p. 1149.

(85) A. H. Heuer and M. Rühle: Ref. (5), p. 1.

(86) V. Lanteri, A. H. Heuer and T. E. Mitchell: Ref. (5), p. 118.

(87) R. Chaim, M. Rühle and A. H. Heuer: J. Am. Ceram. Soc., 68 (1985), 427.

(88) D. Michel, L. Mazerolles and M. Perezy Jorba: J. Mater. Sci., 18 (1983), 2618.

(89) C. M. Wayman: High-temperature Ordered Intermetallic Alloys, ed. by C. C. Koch et al., MSR,
Pittsburgh, Pennsylvania (1985), p. 77.

(90) G. D. Sandrock, A. J. Perkins and R. F. Hehemann: Metall. Trans., 2 (1971), 2769.

(91) C. M. Wayman, I. Cornelis and K. Shimizu: Scripta Met., 6 (1972), 115.

(92) K. Chandra and G. R. Purdy: J. Appl. Phys., 39 (1968), 2176.

(93) K. Otsuka, T. Sawamura and K. Shimizu: Phys. Status Solidi, 5 (1971), 457.

(94) T. Sakuma: J. Mater. Sci., 22 (1987), 4470.

(95) P. G. Shewmon: Transformations in Metals, McGraw-Hill, (1969).

(96) N. Yoshikawa, H. Eda and H. Suto: J. Japan Inst. Metals, 50 (1986), 113.

(97) G. K. Bansal and A. H. Heuer: J. Am. Ceram. Soc., 58 (1975), 235.

(98) R. H. J. Hannink: J. Mater. Sci., 13 (1978), 2487.

(99) D. L. Porter and A. H. Heuer: J. Am. Ceram. Soc., 62 (1979), 298.

(100) R. H. J. Hannink: J. Mater. Sci., 18 (1983), 457.

(101) J. M. Marder, T. E. Mitchell and A. H. Heuer: Acta Metall., 31 (1983), 387.

(102) R. Chaim and D. G. Brandon: J. Mater. Sci., 19 (1984), 2934

(103) T. Sakuma, Y. Yoshizawa and H. Suto: J. Mater. Sci., 20 (1985), 1085.

(104) N. Ishizawa, A. Saiki, T. Yagi, N. Mizutani and M. Kato: J. Am. Ceram. Soc., 69 (1986), c-18.

(105) T. Sakuma, Y. Yoshizawa and H. Suto: J. Mater. Sci., 21 (1986), 1436.

(106) H. M. Kandil, J. D. Greiner and J. F. Smith: J. Am. Ceram. Soc., 67 (1984), 341.

(107) V. Lanteri, R. Chaim and A. H. Heuer: J. Am. Ceram. Soc., 69 (1986), c-258.

(108) A. H. Heuer, R. Chaim and V. Lanteri: Ref. (25), in press.

(109) W. D. Kingery, H. K. Bowen and D. R. Uhlmann: Introduction to Ceramics, 2nd Edition, John Wiley \& Sons, N.Y., (1976).

(110) T. Sakuma: A paper presented at Sintering '87.

(111) H. Suto, T. Sakuma and N. Yoshikawa: Trans. Japan Inst. Metals, 28 (1987), 623.

(112) T. Sakuma and H. Suto: Ref. (25), in press.

(113) M. Rühle, N. Claussen and A. H. Heuer: Ref. (5), p. 352.

(114) R. Chaim, A. H. Heuer and D. G. Brandon: J. Am. Ceram. Soc., 69 (1986), 243. 